\title{
The Effect of Status on Voluntary Contribution ${ }^{1}$
}

\author{
Cagri S. Kumru \\ University of New South Wales \\ and \\ Lise Vesterlund \\ University of Pittsburgh
}

April 2008

\begin{abstract}
Fundraisers often start their campaigns by soliciting the wealthier, more recognized and respected individuals in a community. We examine whether an explanation for such a solicitation ordering may be that people prefer to associate with those of higher social ranking than themselves. Using a simple linear example we demonstrate that concerns for status may give rise to an optimal solicitation ordering similar to that used by fundraisers. Aggregate contributions and earnings are larger when high-status donors are solicited before rather than after those of low status. To investigate this comparative static experimentally we induce a status differential in the laboratory and reverse the contribution order between high- and low-status participants. We find that low-status followers are likely to mimic contributions by high-status leaders and this encourages highstatus leaders to contribute. Contributions are therefore larger when individuals of high status contribute before, rather than after, those of low status.
\end{abstract}

\footnotetext{
${ }^{1}$ We thank participants at seminars at Harvard, NYU, OSU, and Texas A\&M for very helpful comments. We are grateful to the NSF for generous financial support.
} 


\section{Introduction}

Many fundraising campaigns are launched by the announcement of a large initial contribution made by a well-known donor. While the fundraising literature provides substantial advice on how to entice the initial participation of major donors, there is little explanation as to why this is an ideal strategy. Given that these initial donations tend to trigger giving by others it is unlikely that a desire to provide 'red-carpet' treatment is the sole reason for first approaching well-known donors. ${ }^{2}$ For example, characteristic of Brook Astor's philanthropic endeavors was that news about her contributions would cause others to give, "When she gave one donation to the New York Library, for example, three other major gifts - from Bill Blass, Dorothy and Lewis B. Cullman, and Sandra and Fred Rose - all followed, with her generosity cited as the inspiration." 3 So if it is not simply 'special' treatment of major donors, why do fundraisers rely on certain donors to be the initial contributors? What characteristics should we expect of these lead donors?

The economic insights on the optimal solicitation order are recent. In the classic Bergstrom, Blume and Varian (1986) model of voluntary contributions the fundraiser is weakly better off when not announcing past contributions to future donors. The reason is that sequential moves enable the first mover can commit to a small initial contribution and effectively free ride of the contribution of the subsequent contributor (Varian, 1994). As the classic model does not predict announcements, it naturally cannot shed light on which solicitation order may be preferable from the fundraiser's perspective. A number of reasonable extensions of the classical model do however cause announcements to be the preferable strategy, and some of these extensions result in optimal solicitation orderings that correspond with what we typically observe. For example, Andreoni (1998) examines an environment where there are fixed costs associated with providing the charity's output and where simultaneous giving may result in multiple equilibria; some where the non-profit's output is provided and others where it is not. In line with typical fundraising practices he shows that announcing initial contributions may increase giving

\footnotetext{
${ }^{2}$ The chairman of the trustees of Johns Hopkins explains that the reason why the university asks donors for permission to announce their gifts is that "fundamentally we are all followers. If I can get somebody to be the leader, others will follow. I can leverage that gift many times over." The New York Times, February 2, 1997, p. 10.

${ }^{3}$ New York Times, March 30, 2002, p. A13.
} 
as it eliminates the zero-provision outcome, furthermore when it is costly to organize and secure leadership contributions fundraisers will prefer to first solicit the wealthier and most generous donors. Another explanation is proposed by Vesterlund (2003) who extends the classic model by assuming that there is uncertainty about the quality of the charity. Given uncertainty she shows that announcements can be sustained in equilibrium because initial contributions signal the quality of the non-profit to subsequent donors. ${ }^{4}$ Interestingly this signaling model also gives rise to an optimal solicitation ordering consistent with that commonly observed. When the quality of the non-profit is unknown, high-quality organizations find it optimal to first solicit their wealthiest donor. ${ }^{5}$ The reason is not simply that wealthy donors are willing to pay more to investigate the charity, but also that they need to increase their contribution more to convince others that an organization is of high quality.

The purpose of this paper is to examine whether concerns for status may be an additional explanation for the observed solicitation ordering. Lead contributors distinguish themselves not only by being wealthy, but also by being well-known and well-respected. In particular they are often seen as having higher status, or equivalently higher rank in a socially recognized hierarchy. We wish to determine if and how concerns for status may help explain why more well-known and respected individuals tend to contribute first.

Economists have come to recognize that status and concerns for relative standing may affect both economic decisions and the allocation of resources. ${ }^{6}$ Of particular interest have been the theoretical implications of such concerns. For example Frank (1985) examines behavior when status is determined by one's ordinal rank in the distribution of consumption, income, or wealth. Fersthman and Weiss (1993) study the role of social status in a general equilibrium framework. They show that changes in the demand for status may affect the wage structure, the level of aggregate output and economic welfare.

\footnotetext{
${ }^{4}$ Potters, Sefton, and Vesterlund (2007) use experimental methods to examine contributions in an environment where there is uncertainty about the quality of the public good. They show that sequential giving results in larger overall contributions, and that signalling is a likely explanation for this increase in contributions. Furthermore, Potters, Sefton, and Vesterlund (2005) demonstrate that in this environment a sequential contribution ordering will arise endogenously.

${ }^{5}$ To not reveal their type, low-quality organizations may also first solicit wealthy donors. Andreoni (2006) also examines sequential fundraising when there is uncertainty about the quality of the public good.

${ }^{6}$ For early explorations of status see e.g., Smith (1982), Veblen (1926) and Becker (1974).
} 
Congleton (1989) studies status-seeking games in which an individual's utility is not only determined by his absolute consumption, but also by his relative expenditure on statusseeking activities. He shows that some status-seeking activities may generate positive externalities, and that status acquisition need not be wasteful. Hopkins and Kornienko (2004) examine behavior when individuals care about their relative rank in the distribution of consumption of a "positional" good. They find that a result of such preferences is that too many resources are allocated to consumption of the positional good. $^{7}$

While there is substantial work on the theoretical implications of status, there is only limited empirical evidence to demonstrate that concerns for status influence behavior. One exception is Ball, Eckel, Grossman and Zame (2001). Using experimental methods they induce status in the laboratory and examine prices in a competitive market where either the buyer or seller side has low status, while the other side has high status. To secure that there is room for status to influence market outcomes, they use a box-design market, where a vertical overlap in supply and demand ensures that there are multiple equilibrium prices. Surprisingly they find that independent of which side of the market is held by the high-status agents, the high-status group always captures a greater share of the surplus.

Finding that concerns for status can affect behavior in a competitive market suggests that it may be influential in other environments. In particular such concerns may play a substantial role in non-market settings. We want to examine if status concerns affect voluntary contributions to nonprofits, and whether it can give rise to an optimal solicitation ordering consistent with that typically observed. Following Ball et al. (2001) we take the social ranking as given and assume that individuals prefer to associate with those of higher status, but not with those of lower status than themselves. Incorporating such status-motivated preferences into a simple example of a voluntary-contribution

\footnotetext{
${ }^{7}$ See Ball et al. (2001) and Hopkins and Kornienko (2004) for reviews of the status literature. The literature on social identity and prestige relates directly to that on trust. Harbaugh (1998a, 1998b) examines a model where an individual's contribution provides prestige, and he shows that total contributions may increase by using a category reporting plan. Andreoni and Petrie (2004) alter the identification of the participants and information on their contribution in an experimental study. By doing so, they allow social effects such as pride, shame, social comparison and prestige to affect participants' decisions. They find that identity and information matter. Akerlof and Kranton (2000) analyze the effects identity, i.e., a person's sense of self, have on economic outcomes.
} 
model we first show that contributions are sensitive to the order in which high- versus low-status individuals contribute. We then examine the derived comparative statics experimentally.

Our model and experimental design relies on a linear-contribution mechanism. There are two members of each group, and they must each decide whether to contribute to a charity. Contributing incurs a private cost, but generates a benefit for both group members. Incorporating concerns for status in the model and assuming that the two members differ in their status rank we find that the solicitation ordering that maximizes total contributions is one where individuals of high-status contribute prior to, rather than after, those of low status. There are two reasons why this ordering is optimal. First, an initial contribution by a high-status individual encourages those of low status to contribute. Second, knowing that low-status donors mimic the high-status contribution encourages the high-status person to give as well. The latter effect arises because the benefit of subsequent contributions is sufficient to overcome the monetary and status cost associated with giving to the same organization as someone of low status.

To investigate whether concerns for status influence behavior in a voluntary contribution setting we rely on the Ball et al. (2001) procedure to induce status in the laboratory. We pair people in groups of two, where one participant is induced to have higher status than the other. Using a between-subject design we compare the effect on behavior of reversing the contribution order between the two participants. That is, in one treatment the leader is induced to have high status and the follower low status, and in the second treatment the contribution order is reversed. Our experimental results are consistent with the derived comparative statics. Low-status followers mimic the highstatus leaders' contributions, while high-status followers are more reluctant to mimic giving by low-status leaders. Leaders appear to correctly anticipate these responses, and high-status leaders contribute substantially more than low-status leaders. The net effect is an 80 percent increase in total contributions when high-status participants contribute first.

The remainder of the paper is organized as follows. In Section 2, we introduce a simple model for voluntary contributions with status concerned donors, and we examine the interaction between contribution order and status. The predicted comparative statics 
guide our experimental design, which is described in Section 3. The associated results are presented in Section 4, and Section 5 concludes.

\section{A Simple Model of Voluntary Contributions with Status}

In modeling the interaction between concerns for status and charitable giving we may view status as either endogenous or exogenous to the contribution decision. An individual's donation may affect how she is ranked relative to other people, and hence a motivation for giving may be status acquisition. ${ }^{8}$ However an individual's status prior to giving may also influence contribution behavior. Although her donation to the New York Library may have enhanced her status, Brook Astor was already known to be the granddame of philanthropy prior to giving, and it is possible that this initial status influenced her contribution.

We focus on an environment where a status differential exists prior to the individual contributing. Taking the social hierarchy as exogenously given, we use an example to demonstrate how such a differential may influence contributions. Of particular interest is whether, in the presence of status, fundraisers and donors prefer that contributions be made simultaneously or in sequence, and if so who they would prefer contribute first?

To mirror our experimental design we use a simple binary and linear example to illustrate the effect concerns for status may have on voluntary contributions. Suppose two individuals, $\mathrm{A}$ and $\mathrm{B}$, each must allocate a unit endowment to either private consumption $\left(\mathrm{g}_{\mathrm{i}}=0\right)$ or a charity $\left(\mathrm{g}_{\mathrm{i}}=1\right)$. If allocated to private consumption the individual gets a return of one, while an allocation to the charity generates a return of $m$ to both participants. The individual's payoff from the interaction is given by

$$
\pi_{\mathrm{i}}=1-\mathrm{g}_{\mathrm{i}}+\mathrm{m}\left(\mathrm{g}_{\mathrm{A}}+\mathrm{g}_{\mathrm{B}}\right), \mathrm{i} \in\{\mathrm{A}, \mathrm{B}\} .
$$

As others before us we model the charity as a public good. The reason is that as one donor contributes to a charity others, who are concerned for the well-being of the

\footnotetext{
${ }^{8}$ As explained by Akerlof and Kranton (2000): "In a world of social difference, one of the most important economic decisions that an individual makes may be the type of person to be." Thus the motive for contributing to charity may not only be a desire to influence the charity's provision, but also the effect such contributions have on the individual's identity.
} 
recipients of the charity, cannot be prevented from benefitting from this increase in contributions (non-exclusion) and the benefit they experience does not influence that experienced by anyone else (non-rival). We focus on the case where ignoring the status term there is a social dilemma, i.e., $0.5<\mathrm{m}<1$. Implying that absent status it is efficient for both to contribute, but independent of the contribution order neither individual will choose to do so.

To augment this model with a concern for status we assume that individuals are concerned about the status of the individuals they interact with. Specifically following Ball et al. (2001) we assume that individuals want to associate with people who have higher status than themselves and dislike associating with those of lower status. While our results rely on preference for association with those of higher status, the dislike for association with those of lower status only limits the range where our results hold. Association with others can be secured by contributing to the organizations they support, and it can be prevented by not doing so. To capture status concerns we assume that individual i's utility from contributing to the same organization as individual $j$, is an increasing function of the status term $S_{i j}=e_{i} \cdot\left(s_{j}-s_{i}\right) \cdot g_{i} g_{j}$, where $s_{i} \in R^{+}$denotes the individual's status score, and $\mathrm{e}_{\mathrm{i}} \in[0,1]$ the individual's concern for status. Note that in our binary example $\mathrm{g}_{\mathrm{i}} \mathrm{g}_{\mathrm{j}} \in\{0,1\}$. Thus, we assume that the return from giving is larger when contributing to charities with a high-status donor. Combining the payoffs in (1) with the concern for status we consider the simple utility function:

$$
\mathrm{U}_{\mathrm{i}}=1-\mathrm{g}_{\mathrm{i}}+\mathrm{m}\left(\mathrm{g}_{\mathrm{A}}+\mathrm{g}_{\mathrm{B}}\right)+\mathrm{e}_{\mathrm{i}}\left(\mathrm{s}_{\mathrm{j}}-\mathrm{s}_{\mathrm{i}}\right) \mathrm{g}_{\mathrm{A}} \mathrm{g}_{\mathrm{B}}, \mathrm{i} \in\{\mathrm{A}, \mathrm{B}\} .^{9}
$$

The parameters of the model are assumed to be common knowledge. As noted above when $\mathrm{e}_{\mathrm{i}}=0, \mathrm{i} \in\{\mathrm{A}, \mathrm{B}\}$, neither individual contributes to the charity. To demonstrate how concerns for status may influence giving we examine the implications of $\mathrm{e}_{\mathrm{i}}>0$ on our example. Note first that when the other donor has the same status level as herself then independent of the solicitation order the equilibrium reverts back to one with no concerns

\footnotetext{
${ }^{9}$ Our objective is to illustrate the comparative statics that may result when individuals have status concerns. We consider the particularly simple example $\mathrm{U}_{\mathrm{i}}$. In continuous contribution models interior solutions typically require that the status component is some $\mathrm{f}\left(\mathrm{S}_{\mathrm{ij}}\right)$, where $\mathrm{f}^{\prime}>0$, and $\mathrm{f}^{\prime}$ ' $<0$.
} 
for status. Thus, in our linear example no contributions are made when $\mathrm{s}_{\mathrm{A}}=\mathrm{s}_{\mathrm{B}}{ }^{10}$ Consider instead the case where individual $\mathrm{A}$ has more status than $\mathrm{B}$, i.e., $\mathrm{s}_{\mathrm{A}}>\mathrm{s}_{\mathrm{B}}$, and refer to individual A as the high-status agent and individual B as the low-status agent. Suppose that they only differ in their individual status, i.e., they are equally concerned about status, normalizing $\mathrm{e}_{\mathrm{i}}=\mathrm{e}=1$. That is, low-status individuals are as eager to be with someone of high status as the high-status individuals are reluctant to be with someone of low status.

How should a contribution-maximizing fundraiser design his campaign in this environment? Suppose he first solicits the low-status agent, and subsequently the highstatus one. Since in this case the low-status contribution is taken as given, contributing is costly for the high-status follower and she allocates her endowment to private consumption. Knowing that the high-status follower will not contribute, the low-status leader's return from giving is only $\mathrm{m}<1$, and he too allocates his endowment to private consumption. Thus no contributions are made to the charity when the low-status agent is solicited first. The outcome is the same when the two agents contribute simultaneously, with simultaneous giving the high-status agent once again takes the low-status contribution as given and opts not to contribute. Thus, when agents give simultaneously or the low-status agent moves first the equilibrium outcome is the same as when there is no concern for status (i.e., $\mathrm{e}_{\mathrm{i}}=0$ ).

Interestingly, contributions need not be zero when the high-status person is the first to give. The reason is that a low-status follower mimics the high-status contribution when $\mathrm{s}_{\mathrm{A}}-\mathrm{s}_{\mathrm{B}}>1-\mathrm{m}$, that is when the benefit of being associated with someone of high status is sufficient to compensate for the cost of contributing. How does this influence the highstatus leader? The follower's mimicking compensates the leader for the cost she experiences from contributing to the same charity as someone of low status. Specifically, conditional on a low-status follower mimicking her action, a high-status leader contributes if the follower's status is not too low and the status differential is compensated by the net return from the public good, specifically when $\mathrm{s}_{\mathrm{A}}-\mathrm{s}_{\mathrm{B}}<2 \mathrm{~m}-1$. Thus, when the difference in status between the two donors is neither too large nor too small,

\footnotetext{
${ }^{10}$ If there is an interior equilibrium in the model without status, then this equilibrium remains in the model where there is no status differential.
} 
i.e., $2 \mathrm{~m}-1>\mathrm{s}_{\mathrm{A}}-\mathrm{s}_{\mathrm{B}}>1-\mathrm{m}$, contributions can be secured by first soliciting the high-status person, then announcing the contribution and asking the low-status person to give. Note that the condition $\mathrm{s}_{\mathrm{A}}-\mathrm{s}_{\mathrm{B}}<2 \mathrm{~m}-1$ only is relevant when individuals prefer not to associate with those of lower status. When status concerns instead are limited to a preference for association with those of higher status (e.g., $\left.\max \left\{\left(\mathrm{s}_{\mathrm{j}}-\mathrm{s}_{\mathrm{i}}\right), 0\right\} \cdot \mathrm{g}_{\mathrm{A}} \mathrm{g}_{\mathrm{B}}\right)$, then the follower's mimicking will trigger the high-status leader's contribution as long as there is a social dilemma where $2 \mathrm{~m}-1>0$.

While participants of low status prefer to associate with those of higher status, their ability to do so is limited by the contribution ordering. In particular they are only able to associate with those of high status in the sequential-move game where those of highstatus give first.

The comparative statics of our example are consistent with the general results of Romano and Yildirim (2001). Extending Varian's (1994) model to a general class of preferences they show that relative to simultaneous giving, sequential giving increases contributions to a public good when the follower's best response function is increasing in that of the leader and this increase is sufficient to compensate the leader for the cost of contributing.

Interestingly in our example a status differential can give rise to an efficient outcome, where both individuals contribute to the public good. This suggests that status acquisition need not be wasteful or decrease overall welfare. A status differential may facilitate a contribution game, which generates welfare improvements that outweigh statusacquisition costs. While similar in spirit, our result differs from that of Congleton (1989). He demonstrates that acquisition of status need not be wasteful if status is acquired from investing in a good that has positive externalities. In contrast our example demonstrates that existing status differences may influence subsequent behavior and cause an improvement in welfare even when status acquisition is costly.

Our analysis of this simple example provides some important insights. Concerns for status can help explain why fundraisers choose to announce past contributions, and consistent with the frequently observed solicitation ordering, status differentials may cause a contribution-maximizing fundraiser to have an optimal solicitation ordering whereby he first solicits high-status donors. Furthermore, such a solicitation order can 
arise even in the absence of a fundraiser. The reason is that since the high-status individual is better off contributing and triggering the contributions of others, he will volunteer to go first.

\section{Experimental Design}

To further investigate the effect status may have on charitable giving we determine if consistent with our example the contribution ordering of high- and low-status individuals influence giving in an experimental setting. Specifically we study behavior in a voluntary contribution game where following the procedures of Ball et al. (2001) we induce some individuals to have higher status than others. ${ }^{11}$ This procedure secures that participants in the laboratory jointly recognize the status differential, and it helps us make inferences on the effects of status. ${ }^{12}$

Mirroring our example we pair participants in groups of two, where one person is induced to have higher status than the other. We study voluntary contributions in two treatments that only differ in the participants' contribution order. In one treatment participants with high status contribute before those of low status, and in the other, the contribution order is reversed. Thus members of the higher-status group are assigned to one of the two roles (leaders or followers) each facing a member of the low-status group in the other role. An identical protocol was used in each of the two treatments. The protocol consisted of two parts; the first was a status-inducement exercise as in Ball et al. (2001) and the second a sequential voluntary-contribution game. ${ }^{13}$

Upon arrival, participants were seated throughout the laboratory. They were given the first part of the status-inducement exercise as they were asked to answer a trivia quiz which contained ten general knowledge questions with numerical answers. Participants were told they would receive $\$ 5$ for completing the quiz, and that their answers to the quiz would be used to determine their role in the experiment. Once everyone had completed the quiz and it was collected, an experimenter proceeded to hand out the instructions for the sequential voluntary-contribution game.

\footnotetext{
${ }^{11}$ The experiment was programmed and conducted using the software z-Tree (Fischbacher, 1999).

${ }^{12}$ Inducing status differences diminishes the possibility that there is disagreement on who has higher status and reduces the likelihood that our results are driven by individuals of high vs. low status having different preferences. See Section 5 for further discussion.

${ }^{13}$ A copy of the instructions for the experiment can be found in the Appendix I.
} 
While one experimenter read the instructions for the voluntary-contribution part of the experiment, a second experimenter (who was seated towards the front of the room) reviewed the trivia quiz answers and determined which participants would be assigned to either a star-group (high-status) or a no-star-group (low-status). In half the sessions we assigned participants who provided the largest numerical answers to the last question on the quiz to the star-group, and in the remaining sessions the star-group consisted of those with the smallest numerical answer. ${ }^{14}$

Once the instructions for the voluntary contribution game were reviewed participants were asked to calculate payoffs for the possible decisions that may occur in the game. The answers to these questions were then presented on the blackboard. Participants were allowed to ask questions by raising their hand and speaking to the experimenter in private. No communication among participants was allowed.

Having finished instructions to the decision-making part of the experiment, we continued the status-inducement exercise by holding an award ceremony to assign participants to the two groups. We first called out the ID numbers for those who were assigned to the star-group. One by one they were invited to come to the front of the room where they were given a shiny black folder with a gold star as well as a congratulatory ribbon which they were asked to wear for the remainder of the experiment. A public applause was given once all six members of the star-group were standing at the front of the room. Members of the star-group were then seated in the two front rows of the laboratory. The walls of this section were marked by three large gold stars, and the individual computers had a gold-star sticker attached to the board. While seating members of the star-group, members of the no-star-group were asked to come and receive a yellow manila folder, and were then seated in the back two rows of the laboratory.

Once everyone was seated we reviewed the content of the folders. The content of the two types of folders were the same, both included a brief summary of instructions and a record sheet. We then read the summary of instructions and began the voluntary-

\footnotetext{
${ }^{14}$ While our procedure is based on that of Ball et al. (2001) there are small differences. Their quiz consisted of 5 obscure economic questions with numerical answers, and assignment to the star-group was based on the sum of the five numerical answers. Surprisingly they find that status has less of an effect in an "awarded" than in an obviously random-status treatment. They argue that this most likely is because the test was considered unfair. We therefore choose to modify the questions such that they do not relate to economics, and may be considered fairer.
} 
contribution game. The game consisted of 12 contribution rounds. In each round, a star participant was anonymously and randomly paired with a no-star participant, under the stipulation that no participant was paired with another participant twice in a row, and that no two participants could be paired more than twice during a session.

In each round participants were given the choice between two actions $\mathrm{A}$ and $\mathrm{B} .{ }^{15}$ Choosing A gave the participant a $\$ 1$ payoff, while choosing B provided both participants with a payoff of 75 cents. Choosing A corresponds to not contributing $\left(\mathrm{g}_{\mathrm{i}}=0\right)$ and choosing B corresponds to contributing $\left(\mathrm{g}_{\mathrm{i}}=1\right)$. When leaders had made their decisions, it was shown to the follower they were paired with and the follower was asked to select one of the two options. The only variation across treatment was whether the leader had high or low status. We refer to the treatment where members of the star-group were asked to contribute first as the Star-First treatment, and to the treatment where members of the nostar-group were asked to contribute first as the Star-Second treatment. After each round the participants were informed about the choices and payoffs in their game, and they recorded this information on their record sheets.

At the end of the 12 rounds participants were asked to come to a back room where they were paid in private for their participation in the two parts of the experiment. Each session of the experiment lasted a little less than an hour and average earnings were $\$ 18.93$ (with a minimum of $\$ 15.5$ and a maximum of $\$ 23$ ). We ran four sessions of each treatment with 12 participants in each session. A total of 96 participants were recruited from the Pittsburgh Experimental Economics Laboratory (PEEL) subject pool and were randomly assigned to a treatment. No one participated in more than one session of the experiment.

\section{Results}

Our analyses of the data focus on examining the comparative statics of our model. We determine if total contributions to the public good are larger when individuals of high status contribute first, and what the dynamics may be behind such a finding. Specifically we ask if low-status followers are more likely to mimic the leader's contribution, and

\footnotetext{
${ }^{15}$ The voluntary contribution game mirrors that of Potters et al. $(2005,2007)$ when $m=0.75$. We maintain their labelling and refer to the two actions as A and B.
} 
whether in anticipation of such a response high-status leaders contribute more frequently than low-status leaders. While confirmatory answers to these questions will be seen as supportive of the possibility that concerns for status may help explain the solicitation ordering frequently observed, one must keep in mind that the results are sensitive to the status differential we induce in the laboratory.

The participants' behavior in the laboratory suggests that they did care about the status-inducement part of the experiment. They seemed anxious to learn which group they were assigned to, and those assigned to the star-group appeared very pleased with themselves, while those in the no-star-group did not. There is however little evidence that they consciously thought about their assignment when making decisions in the voluntarycontribution part of the experiment. In our open-ended exit survey regarding their voluntary-contribution decisions, only one of our participants made reference to the starvs. no-star assignment. The participants' behavior upon leaving the experiment suggests, however, that they still cared about their assigned role. While all participants were asked to leave their folders and other material by their computer, members of the star-group frequently brought their shiny folders and ribbons with them as they walked through the lab to receive payment, by contrast no-star members always left their materials by their computer. Furthermore, several members of the star-group asked if they could take their ribbons with them.

Despite inducing a potentially small status differential, our results from the Star-First and Star-Second treatments demonstrate a substantial effect from ordering. Figure 1 shows the average group contribution per round. With two people in each group the maximum contribution is 2 . We see that on average group contributions are 80 percent larger when high-status participants contribute first. As usual in public-good games, the frequency of contributions is larger in the first half than in the second half of the experiment, and this decrease in contributions is observed in both treatments. Note however that the difference between treatments does not decrease. Whether we look at the first or second half of the experiment, aggregate contributions remain larger in the Star-First treatments. Using each session as the unit of observation the conservative Mann-Whitney U-test reveals that these differences in aggregate contributions are 
statistically significant, whether we look at the entire experiment or only the first half or second half of the experiment. ${ }^{16}$

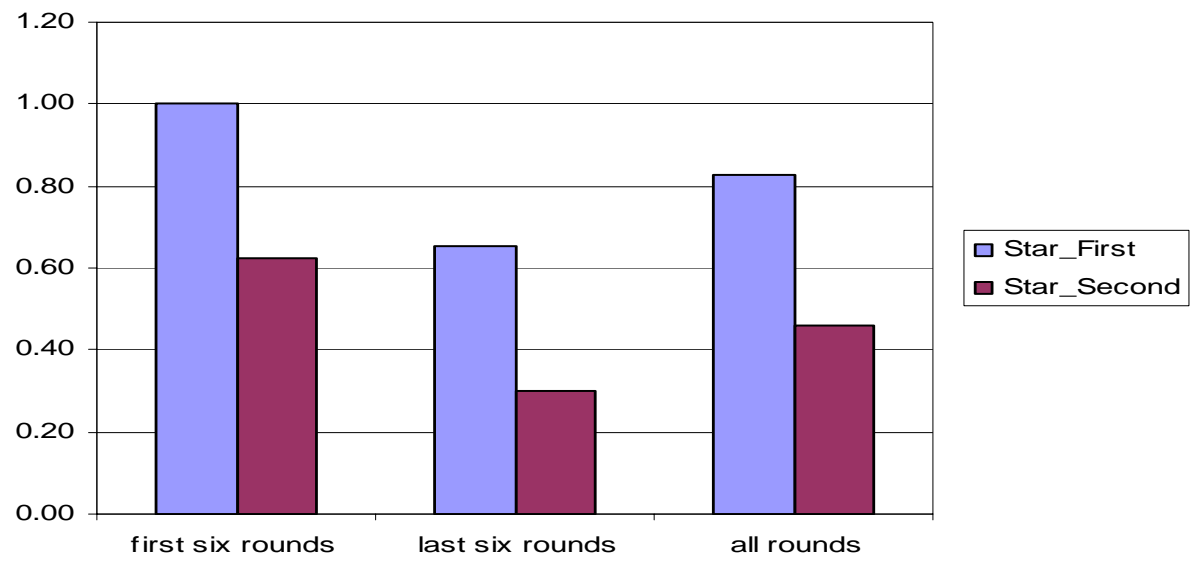

Figure 1: Average Group Contribution per Round

Thus letting the high-status leader contribute first rather than last has a substantial and significant effect on aggregate contributions. Next we examine whether this increase in contributions could be caused by the interaction demonstrated in our theoretical example.

We start by determining whether the frequency by which followers mimic the leader's contribution is larger when the leader has high status. While not contributing remains the payoff-dominant strategy for the followers, Figure 2 shows that a number of followers nonetheless mimic the leader's contribution and that such mimicking is more common in the Star-First treatment. While low-status followers on average mimic highstatus leaders 45 percent of the time, this only happens 30 percent of the time with highstatus followers and low-status leaders. This difference is statistically significant, i.e., we reject the null hypothesis that the follower is less likely to mimic a leader contribution when the high-status participant gives first (one-sided p-value is .0786). In contrast, when the leader does not contribute, only 6 and 5 percent of the followers choose to contribute in Star-First and Star-Second treatments, respectively. Hence, by contributing a leader can increase the probability that a follower contributes by 39 percent in the Star-First

\footnotetext{
${ }^{16}$ The three one-sided p-values are no larger than 0.0571 . A summary of the reported statistical tests can be found in Appendix II.
} 
treatment and by 25 percent in the Star-Second treatment. While this difference may appear small it implies that a payoff-maximizing leader prefers to contribute when she is of high status, but not when she is of low status. Since the cost of contributing is 25 cents, and each contribution by the follower generates a leader payoff of 75 cents, the leader is better off contributing as long as her contribution increases the probability that the follower contributes by 33 percent.

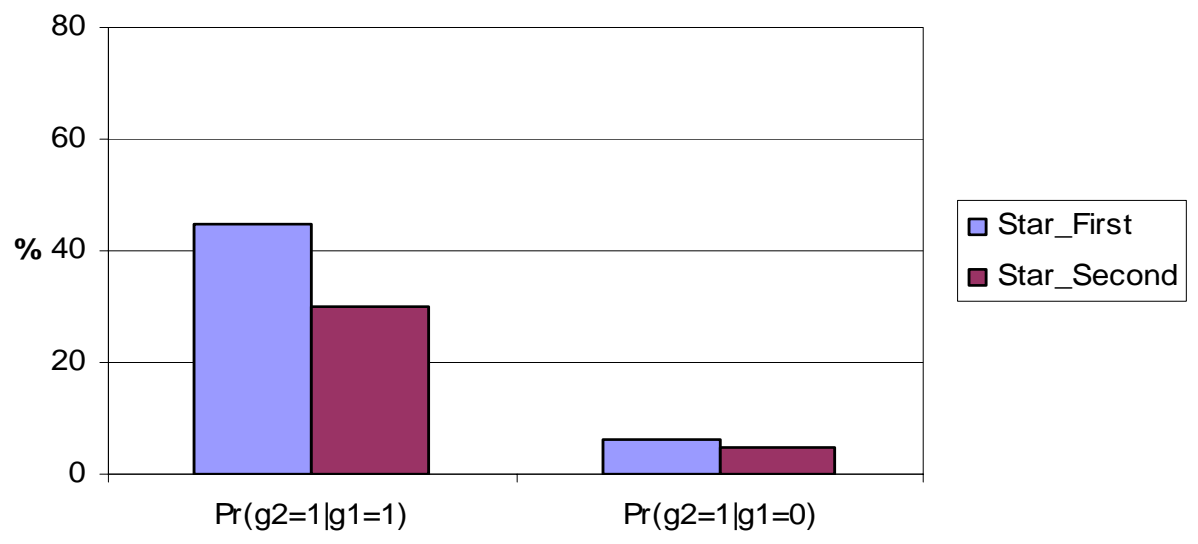

Figure 2: Follower's Conditional Contribution Probabilities

Next we examine if leaders in the two treatments appear to anticipate the follower's response. Figure 3 illustrates the leader's contribution frequency in each treatment. As predicted high-status leaders are more likely to contribute than low-status leaders. While the contribution frequency is 55 percent among high-status leaders, it is only 33 percent among low-status leaders. Despite the decrease in contributions over the course of the game, the difference between the contribution frequencies remains substantial and in the 22-23 percentage-point range. This difference is significant whether we examine the entire experiment, or only the first or second half of the experiment. ${ }^{17}$ The larger contribution rate among high-status leaders suggests that they, from the very beginning of the game, have different expectations about the follower's response, and that this difference in expectations between the two treatments is maintained throughout the game.

${ }^{17}$ One-sided p-values for the three tests are no larger than 0.0429 . 


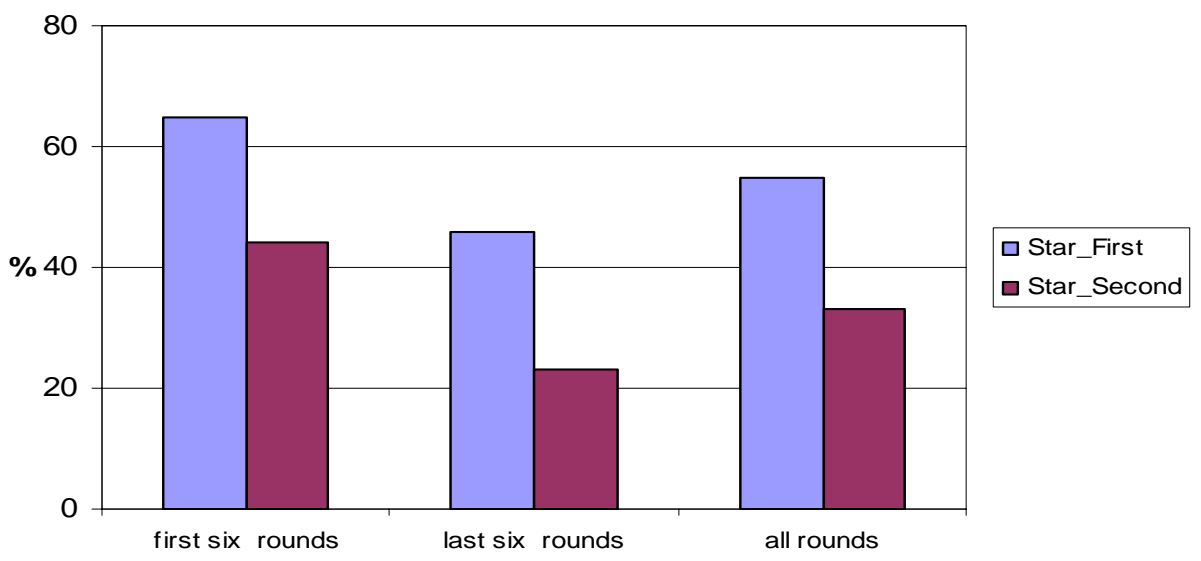

Figure 3: Frequency of Contributions by the Leader

While the larger leader contributions in the Star-First treatment are consistent with our predictions, they are not necessarily what we would have anticipated in light of past experimental results. For example, Hoffman and Spitzer (1985) show that individuals who earn a role in a simple bargaining game feel entitled to that role and tend to make less generous offers. To the extent that our high-status leaders feel that they are entitled to their role of leaders, one may therefore have anticipated that they contribute less, instead of more, than low-status leaders.

Combined the higher leader-contribution rates and the more frequent mimicking in the Star-First treatment has substantial implications on the follower-contribution rates in the two treatments. These are illustrated in Figure 4. The follower-contribution frequency is much larger in the Star-First than Star-Second treatment. While low-status followers contribute 27 percent of the time, the contribution frequency for the high-status follower is only 13 percent. This difference in contributions is significant. ${ }^{18}$

${ }^{18}$ One-sided p-values for all 12, the first six, or the last six rounds are no larger than 0.0571 . 


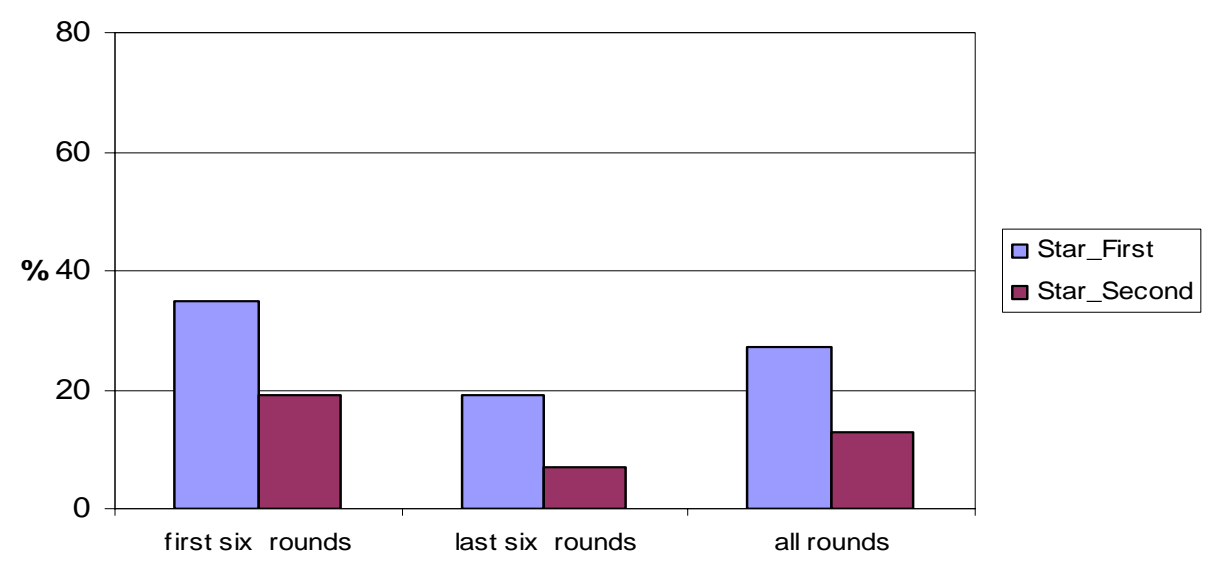

Figure 4: Frequency of Contributions by the Follower

Interestingly behavior in the Star-Second treatment is very similar to what has been seen in experiments absent status. Potters et al. (2007) use a very similar environment to analyze the effects of announcements on contributions when there is uncertainty about the quality of the public good. They observe that if there is no uncertainty and $\mathrm{m}=0.75$, the leader's contribution frequency is 27 percent, and the follower mimics the leader's contribution 33 percent of the time. By comparison in our Star-Second treatment the contribution frequency by low-status leaders is 33 percent, and the likelihood that the high-status follower mimics the contribution is 30 percent. Thus behaviorally status has little if any effect when the first mover has low status. Although this result is consistent with the prediction of our example, this result relied on the equilibrium prediction of zero contributions. Given positive provision we would expect that status decreases giving relative to the scenario absent status. If individuals are reluctant to associate with those of lower status then we would expect the high-status follower to be more reluctant to follow the low-status. The similarity in the mimicking behavior of the high-status follower to that of followers in Potter et al. (2005) suggest that the aversion to association to those of lower status is minimal in our study.

As an alternative explanation for our results it may be argued that perhaps the difference between treatments is caused by followers being likely to mimic behavior of those who are perceived to be more intelligent but not those who are less intelligent. In considering this explanation it is important to recognize that intelligence is considered an 
important status indicator. ${ }^{19}$ Thus if mimicking by low-status followers is driven by a desire to associate with those of greater intelligence then this interpretation is in line with our status model. This is however not the case if individuals mimic the high-status leaders because these are perceived to have a superior understanding of the game. There are a number of reasons why we do not think that the latter is a convincing explanation for our results. First, the examined game is an exceptionally simple one and it is hard to imagine that perceived superior performance on our unrelated trivia quiz would be seen as an indicator of greater game-theoretic insights. Second, if our results are driven by participants mimicking behavior of those who are more intelligent, and not those who are less intelligent. Then we should observe treatment differences both when the leader does and does not contribute. However, when the leader fails to contribute, the contribution rate of the follower is 5-6 percent independent of treatment. Third, if low-status individuals are seen as less intelligent then we would expect high-status followers in the Star-Second treatment to be less likely to mimic their initial contributions, yet the contribution patterns are very similar to those of Potters et al. $(2005,2007)$ where no status is induced. ${ }^{20}$

Another suggested explanation for our results is that perhaps high-status individuals feel more generous once they have been rewarded high status. Note however that while this explanation is consistent with the observation that high-status leaders give more, it is not consistent with the fact that high-status followers give less than low-status followers, nor is it consistent with the high-status follower's contribution frequency being similar to that seen absent status.

Next we examine the effect of status on individual earnings. A common view among economists has been that individuals acquire status not because they value status itself, but rather that they seek it because high status allows higher incomes and better consumption opportunities (see e.g., Postlewaite, 1998). ${ }^{21}$ The prediction that high-status individuals earn more has been confirmed in a couple of studies. For example, Ball and Eckel (1998) examine bargaining games and show larger high-status earnings. Ball et al.

\footnotetext{
${ }^{19}$ E.g., Nie et al. (1996) argue that education is a good proxy for relative status.

${ }^{20}$ Certainly the exit questionnaire provided no evidence that participants perceived members of the star group as being more intelligent.

${ }^{21}$ In contrast, biology and evolutionary psychology propose that people pursue status as an (emotional) goal in itself, independent of the other benefits status may engender.
} 
(2001) show that this finding extends to competitive markets, where low-status individuals appear to bear the cost of associating themselves with the high-status individuals. Similarly Glaeser et al. (2000) find evidence suggesting that individuals with high-status characteristics tend to extract larger rents from a voluntary non-market transaction, namely a trust game.

The prediction of our simple model, however, is not that high-status individuals have higher earnings than those of low status. While no earnings differential is predicted in the Star-Second treatment, differences may arise in the Star-First treatment. Specifically, when agents have heterogeneous status concerns it is entirely possible that earnings of the high-status leader be smaller than those of the low-status follower. The reason is that low-status followers only contribute when a high-status leader has already done so. Suppose that only some low-status followers are willing to mimic the contribution of a high-status leader, and that the proportion mimicking is large enough to provide some leaders with an incentive to contribute. Such an environment will cause the average contributions of high-status leaders to be larger than those of low-status followers, and as a result individuals of high-status will on average earn less than those of low-status.

Table 1 reports average earnings from the two treatments. Focusing first on the StarFirst treatment, we see that consistent with our example, but in contrast to previous research, high-status leaders earn less than their low-status followers. ${ }^{22}$ The earnings differential in the Star-Second treatment is however not consistent with our example. Rather than finding no difference we see low-status leaders earning less than their highstatus followers. ${ }^{23}$ Thus, independent of treatment followers earn more than leaders. ${ }^{24}$ This finding suggests that in contrast to our theory it need not be the case that, absent a fundraiser, a high-status individual will volunteer to contribute first. Note however that this conclusion relies critically on there only being one follower. If the high-status contributor can trigger the contributions by many followers then the benefit from being a first contributor will increase.

\footnotetext{
${ }^{22}$ One-sided $\mathrm{p}=0.0143$ over the 12 rounds or the first six rounds, and $\mathrm{p}=0.0286$ for the last six rounds.

${ }^{23}$ One-sided $\mathrm{p}=0.0143$ over the 12 rounds or the first six rounds, and $\mathrm{p}=0.0429$ for the last six rounds.

${ }^{24}$ For star participants we can reject the hypothesis that leader earnings exceed those of followers over the 12 rounds and the first six rounds (one-sided $\mathrm{p}=0.0286$ and $\mathrm{p}=0.0429$ respectively). We cannot reject this hypothesis during the last six rounds $(\mathrm{p}=0.1357)$. For non-stars we reject the hypothesis that earnings are larger as a leader than follower overall and for both the first and second half of the experiment (one-sided $\mathrm{p}=0.0143$ in all three cases).
} 
Table 1: Average Earnings (\$) per Participant per Session

\begin{tabular}{lll}
\hline & Leaders & Followers \\
\hline Star-First & 12.8 & 16.1 \\
Star-Second & 12.2 & 14.6 \\
\hline
\end{tabular}

In addition to contributions being larger when the high-status person gives first, Table 1 reveals that the sum of leader and follower earnings is significantly larger in the StarFirst treatment. ${ }^{25}$

\section{Conclusion}

Fundraisers often start their campaigns by soliciting the wealthier, more recognized, and respected individuals in a community. We have examined whether concerns for status may help explain such a solicitation strategy. Assuming that individuals prefer to associate with those of higher status, we use a simple linear example to show that contributions increase when individuals of high status are asked to give before rather than after those of lower status. In fact our example shows that the charity, fundraiser, and associated donors all will benefit from the frequently observed solicitation order.

To examine the effect of status in a laboratory setting we opted to induce status rather than to rely on individual characteristics that have been thought to be associated with high status, e.g., gender and height. ${ }^{26}$ There are several reasons why we chose this option. First, in our study it is crucial that participants agree on who has high versus low status. Given that individuals have several different status characteristics, it would be difficult to secure that the status dimension we would sort by corresponded with the one participants focused on. Second, even if individuals were to pay attention to the dimension by which

\footnotetext{
${ }^{25}$ One-sided $\mathrm{p}=0.0143$ over the 12 rounds and the first six rounds, and $\mathrm{p}=0.0571$ for the last six rounds.

${ }^{26}$ Bohnet and Hong (2007) examine the effect existing status characteristics may have behavior. Using individual characteristics to classify individual status (e.g., gender, race, religion), they find that while lowand high-status groups are equally unlikely to trust others, the motives for distrust differ. Individuals with high-status characteristics do not trust because they fear betrayal, and those with low-status characteristics do not trust for fear of inequality (but are indifferent to the risk of betrayal). Since individuals are not aware of the characteristics of their opponent in the study, they examine only the effect an individual's status has on own behavior. Glaeser et al. (2000) measure an individual's status by characteristics such as whether you have a sexual partner, drink alcohol on weekends, and family education. They too find little effect of status on trusting behavior, but find that those of higher status elicit more trust worthiness.
} 
we sort them, there may not be agreement on what constitutes high or low status. For example, individuals may disagree on how, say, geeks or jocks rank in the social hierarchy. Third, and perhaps most importantly, commonly accepted status characteristics may not only be indicative of an individual having higher status, but also of them having different preferences. For example, while gender and height commonly are used to characterize an individual's status, others have argued that preferences also differ along these dimensions. For example, some studies have found males to be more risk seeking, less reciprocating, more trusting, and less altruistic than females. ${ }^{27}$ If this constitutes a correct gender characterization then a study using males (as high status) and females (as low status) may find results consistent with the predicted comparative statics simply because preferences differ systematically by gender. In particular, we may be mislead to interpret the results as suggesting that status influences behavior, when instead the results are caused by generous and reciprocating female followers being more likely to mimic the leader's action, and the risk seeking more trusting male leaders being more willing to make an initial contribution. ${ }^{28}$

Despite inducing a small status differential in the laboratory, the evidence from our laboratory experiment is nonetheless consistent with the predicted dynamics of our model. When individuals who are induced to have high status contribute first, low-status followers are likely to mimic their contribution, whereas high-status followers are more reluctant to mimic the contributions of low-status leaders. Leaders appear to anticipate this response, and the contribution frequency for high-status leaders is much greater than that of those with low status. The net result is an 80 percent increase in contributions when high-status individuals contribute before rather than after individuals of low-status.

\footnotetext{
${ }^{27}$ E.g., Croson and Buchan (1999) and Chaudhuri and Gangadharan (2007) find that men exhibit greater trust and women show higher levels of reciprocity. Eckel and Grossman (1997a) find that women are more risk averse and Eckel and Grossman (1997b) find that females are more altruistic. Andreoni and Vesterlund (2001) describe a more complex picture of gender differences in altruism. See Eckel and Grossmann (2002a, 2002b) as well as Croson and Gneezy (2004) for reviews of experimental research on gender differences.

${ }^{28}$ Taller people have also been found to be less altruistic than shorter people (Harbaugh et al., 2003). Persico et al. (2004) find that while taller men earn more than short ones, this correlation can be explained using height at age 16. Height as an adult does not add any additional explanatory power. They attribute this to the fact that taller adolescents report have larger social networks, which they hypothesize lead to the development of skills that are valuable in the labor market. Thus observed differences between short and tall people need not be due to a status differential.
} 
To return to our initial questions we therefore find evidence to suggest that a contribution maximizing fundraiser will benefit from first soliciting donors who have a high social ranking, and then announcing their contributions to those of lower ranking. ${ }^{29}$ Much as in the signaling model by Vesterlund (2003) it is not merely a question of having a lead contribution, but also who made the lead contribution. ${ }^{30}$ Our study suggests that the characteristics of this lead donor will play an important role for the resulting contribution behavior. While lead contributions by high-status individuals have a substantial effect on giving, lead contributions by low-status individuals do not.

Of course it appears that fundraisers have already figured out which solicitation ordering to use. In fact their practices were the main motive for our examination of status. However when fundraisers are asked why they start by soliciting the wealthier and more prominent individuals, their explanations tend to focus on the fact that this strategy helps create enthusiasm around the campaign. Our paper has shown both theoretically and experimentally that an explanation for this 'enthusiasm' may be that individuals like to associate with those who have higher status than themselves. When asked if the commonly used strategy may work because it enables subsequent donors to associate with the initial donors, one fundraiser's commented that indeed the strategy appears to work well when it enables new money to associate with old money.

\footnotetext{
${ }^{29}$ Note that fundraisers may also opt to not announce initial contributions and instead let donors contribute simultaneously. Potters et al. (2007) observe that when there is no uncertainty and $m=0.75$, average contributions in the simultaneous-move and the sequential-move games are almost identical. As demonstrated earlier, the difference between contribution levels in the Star-Second treatment and Potters et al. sequential-move treatment is negligible. This may be seen as evidence that a fundraiser will not prefer simultaneous-move game in this environment.

${ }^{30}$ Croson and Shang (2007) show that the gender of past donors is important when individuals decide whether to mimic their contribution. While women are influenced by women, men are influenced by men.
} 


\section{References}

Akerlof, G. A., and R. E. Kranton, "Economics and Identity," Quarterly Journal of Economics, 115, 2000, 715-753.

Andreoni, J., "Toward a Theory of Charitable Fundraising," Journal of Political Economy, 106 (6), 1998, 1186-1213.

Andreoni, J., "Leadership Giving in Charitable Fund-Raising." Journal of Public Economic Theory, 8 (1), 2006, 1-22.

Andreoni, J., and L. Vesterlund, "Which is the Fair Sex? Gender Differences in Altruism," Quarterly Journal of Economics, 116, 2001, 293-312.

Andreoni, J., and R. Petrie, "Public Goods Experiments Without Confidentiality: A Glimpse into Fund-Raising,” Journal of Public Economics, 88, 2004, 1605-1623.

Ball, S., and C. Eckel, "The Economic Value of Status," Journal of Socio-Economics, 27, 1998, 495-514.

Ball, S., C. Eckel, P. J. Grossman, and W. Zame, "Status in Markets," Quarterly Journal of Economics, 116, 2001, 161-188.

Becker, Gary S., "A Theory of Social Interactions," Journal of Political Economy, 82, 1974, 1063-1093.

Bergstrom, Theodore, Lawrence Blume and Hal Varian, "On the Private Provision of Public Goods," Journal of Public Economics, 29(1), 1986, 25-49.

Bohnet, I., and K. Hong, "Status and Distrust: The Relevance of Inequality and Betrayal Aversion,” Journal of Economic Psychology, 28, 2007, 197-213.

Chaudhuri, A., and L. Gangadharan, "An Experimental Analysis of Trust and Trustworthiness," Southern Economic Journal, 2007, 73(4), 959-985.

Congleton, R. D., "Efficient Status Seeking: Externalities, and the Evolution of Status Games," Journal of Economic Behavior and Organization, 11, 1989, 175-190.

Croson, R., and N. Buchan, (1999), "Gender and Culture: International Experimental Evidence from Trust Games,” American Economic Review, 89, 1999, 386-91.

Croson, R. and U. Gneezy, “Gender Differences in Preferences,” Working Paper, 2004

Croson, R. and J. Shang, "Field Experiments in Charitable Contribution: The Impact of Social Influence on the Voluntary Provision of Public Goods.” Working Paper, 2007 
Eckel, C. and P. Grossman, "Are Women less Selfish than Men? Evidence from Dictator Experiments," Economic Journal, 108, 1997a, 726-35.

Eckel, C., P. Grossman, N. Lutz, and V. Padmanbhan, "Playing it Safe: Men, Women, and Risk Aversion," Working Paper, $1997 \mathrm{~b}$.

Eckel, C., and P. Grossman, "Differences in the Economic Decisions of Men and Women: Experimental Evidence." Forthcoming in Handbook of Experimental Results, edited by C. Plott and V. Smith. New York, Elsevier, 2002a.

Eckel, C., and P. Grossman, "Sex and Risk: Experimental Evidence," Forthcoming in Handbook of Experimental Results, edited by C. Plott and V. Smith. New York, Elsevier, $2002 b$.

Fershtman, C., and Y. Weiss, "Social Status, Culture and Economic Performance," Economic Journal, 103, 1993, 946-959.

Fischbacher, Ur, "z-Tree-Zurich Toolbox for Readymade Economic ExperimentsExperimenter's Manual," Working Paper Nr. 21, Institute for Empirical Research in Economics, University of Zurich, 1999.

Frank, Robert H., "The Demand for Unobservable and Other Positional Goods," American Economic Review, 75, 1985, 101-116.

Glaeser, E., D. Laibson, J. Scheinkman, and C. Soutter, "Measuring Trust," Quarterly Journal of Economics, 115, 2000, 811-846.

Harbaugh, W. T., "What Do Donations Buy? A Model of Philanthropy Based on Prestige and Warm Glow," Journal of Public Economics, 67, 1998a, 269-284.

Harbaugh, W. T., "The Prestige Motive for Making Charitable Transfers," American Economic Review, Papers and Proceedings, 88, 1998b, 277-82.

Harbaugh, W., K. Krause, and S. Liday, “Bargaining by Children,” Working Paper, 2003.

Hoffman, E., and M. L. Spitzer, "Entitlements, Rights, and Fairness: An Experimental Examination of Subjects' Concepts and Distributive Justice," Journal of Legal Studies, $14,1985,259-297$.

Hopkins, E., and T. Kornienko, "Running to Keep in the Same Place: Consumer Choice as a Game of Status," American Economic Review, 94, 2004, 1085-1107.

Nie, N. H., J. Junn, and K. S. Barry, "Education and Democratic Citizenship in America," University of Chicago Press, 1996, Chicago, Illinois. 
Persico, N., A. Postlewaite, and D. Silverman, "The Effect of Adolescent Experience on Labor Market Outcomes: The Case of Height," Journal of Political Economy, 112, 2004, 1019-1053.

Postlewaite, Andrew, “The Social Basis of Interdependent Preferences," European Economic Review, 42, 1998, 779-800.

Potters, J., M. Sefton, and L. Vesterlund, "After You-Endogenous Sequencing in Voluntary Contribution Games," Journal of Public Economics, 89, 2005, 1399-1419.

Potters, J., M. Sefton, and L. Vesterlund, "Leading-by-Example and Signaling in Voluntary Contribution Games: An Experimental Study," Economic Theory. 2007, 33, 169-182.

Romano, R., and H. Yildirim, "Why Charities Announce Donations: A Positive Perspective," Journal of Public Economics, 81, 2001, 423-447.

Smith, Adam, "The Theory of Model Sentiments," D.D. Raphael and A.L. MacFie, eds. (Indianapolis, IN: Liberty Press/Liberty Classics, 1982).

Varian, Hal R., "Sequential Provision of Public Goods," Journal of Public Economics, $53,1994,165-186$.

Vesterlund, Lise, "The Informational Value of Sequential Fundraising," Journal of Public Economics, 87, 2003, 627-657.

Veblen, Thornstein, 1926, "A Theory of Leisure Class: An Economic Study of Institutions," Vanguard Press, New York. 


\section{Appendix I \\ Experimental Instructions}

Preparation:

- $\quad$ Gold stars attached to the wall towards the front of the lab.

- $\quad$ Prepare folders with summary of instructions and record sheet (six shiny black

Arrival: folders with stars on the front and six yellow manila folders).

- $\quad$ Participants are seated in the lab

Welcome and Consent:

- $\quad$ Thank you for coming.

- $\quad$ Before we begin we will hand out a consent form.

- $\quad$ Please read the consent form carefully, put your initials at the bottom of the first page and sign it at the bottom of the second page. Your signature will indicate your willingness to participate in the experiment.

- $\quad$ After you have signed the consent form we will come around to collect it.

- Collect forms.

Quiz:

- $\quad$ As indicated in the consent form there are two parts of this experiment.

- $\quad$ First, you will be asked to answer a quiz, and then you will participate in a decision-making experiment.

- $\quad$ We will start with the quiz [hand out the quiz].

- $\quad$ The answers you give on this quiz will determine to which one of two groups you will be assigned for the decision making part of the study. At the end of the experiment you will receive $\$ 5$ for having completed the quiz.

- $\quad$ At the top of the quiz there is a yellow post-it note with an ID number on it. This is the number we will use to identify you in the experiment. Please remove your ID number and put it in a safe place.

- $\quad$ Please go ahead and answer the quiz. 


\section{Quiz}

Please take a few moments to answer the quiz. If you do not know an answer please give your best guess. When you have completed the quiz, please turn it over and we will come around to collect it. Your score on the quiz determines to which one of two groups you will be assigned for the decision making part of the study. At the end of the experiment you will receive $\$ 5$ for completing the quiz.

1. How many days are there in a non-leap year?

2. How many degrees Fahrenheit correspond to 0 degrees Celsius?

3. How many red stripes are there in the American flag?

4. How many days are there in the month of February during a leap year?

5. How many members are there of the U.S. Senate?

6. How many floors are there in the Cathedral of Learning?

7. What year was the University of Pittsburgh founded?

8. What are the costs of sending a one-ounce first-class letter within the United States?

9. How many acres is the main campus of the University of Pittsburgh?

10. How many millions of dollars did the University of Pittsburgh receive in research money from the National Institute of Health between 1995 and 2002 ? 
- $\quad$ Collect trivia quiz and hand out instructions.

- $\quad$ Score quiz in the back of the room - visible to the participants. The 50\% who provide the largest numerical answers to question 10 are assigned to the stargroup in half of sessions and assigned to the no-star-group in the other half..

\section{Decision-Making Experiment:}

- $\quad$ While we score your quiz we will go over the instructions for the decisionmaking experiment. Please follow along as I read the instructions out loud.

\section{Instructions}

This is an experiment about decision making. There are twelve people in this room participating in the experiment. Six participants will be given the role of 'first-mover,' the other six will be given the role of 'second-mover.' Your score on the quiz determines whether you are a first mover or a second mover. Your role will be the same throughout the experiment.

The experiment will consist of twelve rounds. In each round, each first-mover will be anonymously and randomly paired with a second-mover. This will be done in such a way that you will not be paired with the same person two rounds in a row. Nor will you be paired with the same person more than two times. You will never know the identity of the other person in your pair, nor will that person know your identity.

\section{Choices and earnings}

In each round you have to choose between two options: A or B. The other person in your pair also has to choose between options A and B. Your earnings in each round will depend on the decisions made by you and the person you are paired with for that round.

If you choose A, 100 cents are added to your earnings and 0 cents are added to the earnings of the person with whom you are paired. Likewise, if the person you are paired with chooses A, 100 cents are added to his or her earnings and 0 cents are added to your earnings.

If you choose B, 75 cents are added both to your earnings and to the earnings of the other person in your pair (irrespective of whether that person chooses A or B). Likewise, if the other person in your pair chooses B, 75 cents are added both to his or her earnings and to your earnings (irrespective of whether you choose A or B).

\section{Procedure and information}

In the first stage of a round the first-mover will enter a choice (A or B). Then, in the second stage, the second-mover will enter a choice (A or B). Before making his or her choice the second-mover will be informed of the first-mover's choice. 
When all the second-movers have made their choices, the result of the round will be shown on your screen. The screen will list the choices made by you and the other person in your pair, and the amounts earned by you and the other person in your pair. You should then record this information on your Record Sheet.

You must not talk to the other participants or communicate with them in any way during the experiment. If, at any stage, you have any questions raise your hand and the experimenter will come to where you are sitting to answer them.

\section{Quiz}

To make sure everyone understands how earnings are calculated, we are going to ask you to complete a short quiz. Once everyone has completed the quiz we will go over the answers. If you finish the quiz early, please be patient. For each question you have to calculate earnings in a round for you and the other person in your pair. Please raise your hand if you have any questions.

$$
\begin{array}{ll}
\text { your } & \text { other's } \\
\text { earnings } & \text { earnings }
\end{array}
$$

1. You choose A and the person you are paired with chooses A?

2. You choose A and the person you are paired with chooses B?

3. You choose B and the person you are paired with chooses A?

4. You choose B and the person you are paired with chooses B?

-When all participants have completed the quiz go over the answers using the black board.

Assignment to groups:

- We have completed the instructions for the decision-making part of the experiment, and based on the results of your quiz we will now assign you to be either a first or second mover in the experiment.

- $\quad$ Those who received the high score on the quiz are assigned to what we will refer to as the star-group. The members of the star-group will be first movers in the experiment. Individuals who received a low score will be assigned to the no-star-group and will be second movers in the experiment.

- We will first call out the ID numbers for those who received a high enough score to be part of the star-group.

- $\quad$ Once you hear your ID number called please come to the front of the class. 
- $\quad$ Once you get up here Cagri will give you a folder with a summary of the instructions and your record sheet as well as a ribbon to congratulate you. Please wear this ribbon for the rest of the experiment. [hand out ribbons and shinny black folders]

- $\quad$ Please remain standing at the front of the room until all members of the stargroup have been found.

- $\quad$ Call out ID numbers

- $\quad$ Let's give the Star-group a round of applause.

- $\quad$ Members of the star-group will be seated in the two front rows of the lab. If the no-star people could please come up and get your folders with a summary and record sheet (Cagri hand out yellow manila folders, Lise seat star-group towards front )

- $\quad$ If the members of the no-star-group can take a seat the last two rows. (Cagri direct them)

- $\quad$ Before we begin let us summarize the rules of the experiment by reading through the summary in your folder.

\section{Summary}

The rules of the experiment are as follows:

1. If you received a star for your performance on the quiz you are a first mover, if you did not receive a star you are a second mover.

2. You will be making decisions over 12 rounds. The sequence of each round is as follows:

a. Each first-mover is randomly paired with a second-mover.

b. The first-mover chooses between A and B.

c. The second mover is informed of the first-mover's choice, and chooses between $\mathrm{A}$ and $\mathrm{B}$.

d. Both the first-mover and the second-mover are informed of the results of the round and record them on their Record Sheet.

3. After round 12 the experiment ends and each participant is paid his or her accumulated earnings from the twelve rounds, plus $\$ 5$ for completing the quiz. Payments are done in private and in cash.

- $\quad$ Point to the first two rows "you will be the first movers," and point to the last two rows "you will be the second movers."

- We are now ready to begin the decision-making part of the experiment. At various times you will have to wait for others to make their decisions. When that happens please be patient. If you have a question at any time, just raise your hand. Be sure to click OK when you have finished reading the content on the screen. 


\section{Appendix II}

Table A.1: Average Contribution per Round

\begin{tabular}{ccccc}
\hline \hline & & $\mathrm{g}_{1}$ & $\mathrm{~g}_{2}$ & $\mathrm{G}$ \\
\hline All rounds & Star-First & .552 & .274 & .826 \\
& Star-Second & .333 & .128 & .461 \\
\hline First 6 rounds & Star-First & .638 & .354 & .992 \\
& Star-Second & .437 & .187 & .624 \\
\hline Last 6 rounds & Star-First & .458 & .194 & .652 \\
& Star-Second & .231 & .069 & .300 \\
\hline \hline
\end{tabular}

Table A.2: Average Earnings (\$) per Round

\begin{tabular}{ccccc}
\hline \hline & & $\begin{array}{c}\text { earnings for } \\
\text { first mover }\end{array}$ & $\begin{array}{c}\text { earnings for } \\
\text { second } \\
\text { mover }\end{array}$ & $\begin{array}{c}\text { Total } \\
\text { earnings }\end{array}$ \\
\hline All rounds & $\begin{array}{c}\text { Star-First } \\
\text { Star- }\end{array}$ & 1.067 & 1.345 & 2.412 \\
& Second & 1.013 & 1.217 & 2.230 \\
\hline First 6 & Star-First & 1.104 & 1.395 & 2.499 \\
rounds & Star- & 1.031 & 1.281 & 2.312 \\
& Second & & & \\
\hline Last 6 & Star-First & 1.031 & 1.295 & 2.326 \\
rounds & Star- & .994 & 1.154 & 2.148 \\
& Second & & & \\
\hline \hline
\end{tabular}

Table A.3: Conditional Probabilities (\%) per Round

\begin{tabular}{cccc}
\hline \hline & & $\operatorname{Pr}\left(\mathrm{g}_{2}=1 \mid \mathrm{g}_{1}=1\right)$ & $\operatorname{Pr}\left(\mathrm{g}_{2}=1 \mid \mathrm{g}_{1}=0\right)$ \\
\hline All & Star-First & 45 & 6 \\
rounds & Star-Second & 30 & 5 \\
\hline First 6 & Star-First & 52 & 6 \\
rounds & Star-Second & 34 & 9 \\
\hline Last 6 & Star-First & 37 & 6 \\
rounds & Star-Second & undetermined $^{31}$ & 2 \\
\hline
\end{tabular}

${ }^{31}$ None of the first movers contributed in the last six rounds of a session. Looking at the remaining three sessions the average is 26 . 
Table A.4: Treatment Effects on Contributions:

One-sided p-values for test that Star-First $\leq$ Star-Second

(Mann-Whitney U-test)

A: First Contribution:

\begin{tabular}{cc}
\hline \hline All rounds & 0.0143 \\
First 6 rounds & 0.0286 \\
Last 6 rounds & 0.0429 \\
\hline \multicolumn{1}{c}{ B: Second Contribution: } \\
\hline \hline All rounds & 0.0143 \\
First 6 rounds & 0.0143 \\
Last 6 rounds & 0.0571 \\
\hline \multicolumn{2}{c}{ C: Total Contribution: } \\
\hline \hline All rounds & 0.0143 \\
First 6 rounds & 0.0143 \\
Last 6 rounds & 0.0571 \\
\hline \hline
\end{tabular}

Table A.5: Treatment Effects on Mimicking Behavior:

One-sided p-values for test that Star-First $\leq$ Star-Second

(Mann-Whitney U-test)

$$
\operatorname{Pr}\left(\mathrm{g}_{2}=1 \mid \mathrm{g}_{1}=1\right)
$$

\begin{tabular}{cc}
\hline \hline All rounds & 0.0786 \\
First 6 rounds & 0.0571 \\
Last 6 rounds & Undetermined \\
\hline \hline
\end{tabular}

Table A.6: Treatment Effects on Average Earnings per Round:

One-sided p-values for test that Star-First $\leq$ Star-Second

(Mann-Whitney U-test)

A: Donor 1's Earnings

\begin{tabular}{cc}
\hline \hline All rounds & 0.0571 \\
First 6 rounds & 0.0571 \\
Last 6 rounds & 0.1357 \\
\hline \hline
\end{tabular}

B: Donor 2's Earnings

\begin{tabular}{cc}
\hline \hline All rounds & 0.0143 \\
First 6 rounds & 0.0143 \\
Last 6 rounds & 0.0429 \\
\hline \hline & C: Total Earnings \\
\hline \hline All rounds & 0.0143 \\
First 6 rounds & 0.0143 \\
Last 6 rounds & 0.0571 \\
\hline \hline
\end{tabular}

